DOI: $10.17805 / z p u .2016 .4 .19$

\title{
Культурологические практики в образовании: конструктивный потенциал интегрированного урока
}

\author{
М. С. ИНКИЖЕКОВА \\ (ИНСТИТУТ РАЗВИТИЯ ОБРАЗОВАНИЯ СВЕРДЛОВСКОЙ ОБЛАСТИ, \\ УРАЛЬСКИЙ ЮРИДИЧЕСКИЙ ИНСТИТУТ МИНИСТЕРСТВА ВНУТРЕННИХ ДЕЛ \\ РОССИЙСКОЙ ФЕДЕРАЦИИ)
}

В связи с введением Федеральных государственных образовательных стандартов становится актуальным освоение интегративного подхода как одного из феноменов культурологических практик в образовании, ознакомление с его основными принципами и сущностью. Потребность в новых образовательных технологиях, инновационных приемах и методах, используемых в рамках интегративного обучения, обусловлена объективной необходимостью совершенствования профессионально-педагогических компетенций учителей. Интегрированные уроки также позволяют сформировать у учащихся целостное и вместе с тем многоуровневое представление о мире.

В статье представлен пример: алгоритм работы по планированию и организации интегративного урока по теме «М. П. Мусоргский. Сюита "Картинки с выставки". Десятая (финальная часть) сюиты "Богатырские ворота. В стольном городе во Киеве"». Автор показывает, что данная тема с привлечением учебного материала по истории, обществознанию, а также дисциплин предметной области «Искусство» позволяет взаимосвязанно не только раскрыть мир художественных образов, но и обратиться к актуальным проблемам современной социокультурной действительности.

Автор делает вывод о том, что урок, построенный на межпредметной интеграции разноуровневых и разнопредметных знаний в образовательном пространстве модернизирующейся школы, предстает конструктивным вариантом систематизации учебного материала. В контексте интегрированного урока по-новому раскрывается функциональная роль педагога, который выступает в роли не столько транслятора знаний, сколько фасилитатора - помощника и наставника.

Ключевые слова: интегрированный урок; межпредметная интеграция; педагог-фасилитатор; культурологические практики; М. П. Мусоргский; история России; терроризм; Золотые ворота

\section{ВВЕАЕНИЕ}

$\mathrm{B}$ модернизирующемся пространстве российского образования практики интегративного обучения еще не получили должного распространения и, как правило, представлены отдельными примерами интегрированных уроков, построенных на основе межпредметных связей.

Межпредметная интеграция, как справедливо отмечают многие современные ученые (см.: Виневская, 2014; Гриценко, 2008; Игнатов, Игнатова, 2013; Харунжев, Харунжева, 2003), представляет собой один из конструктивных вариантов систематизации учебного материала, так как позволяет изучить определенную тему с привлечением необходимого учебного материала из других смежных дисциплин. При этом указанный вид интеграции может иметь как «горизонтальную», так и «вертикальную» структуру.

При «горизонтальной» интеграции устанавливаются межпредметные связи с учетом наличия одного общего предметного поля, созданного путем наложения учебного материала разных дисциплин. «Вертикальная» интеграция предполагает установление разноуровневых межпредметных связей. Но и в первом, и во втором случае це- 
лью межпредметной интеграции выступают предметные, метапредметные и личностные компетенции учащихся.

Что касается учебных дисциплин предметной области «Искусство», то особенно хочется выделить возможность задействовать широкий спектр средств познания (образных и понятийных, чувственных и абстрактных) в их взаимодействии. Более того, интегрированный урок, выстроенный на основе межпредметных связей, может быть организован не только на основе разнопредметных знаний, но и с опорой на разные виды деятельности, которые через взаимное их проникновение и обогащение позволяют не только осмыслить, но и «почувствовать» особенности изучаемых объектов, «пережить» опыт освоения нового знания.

\section{ИНТЕГРИРОВАННЫЙ УРОК: \\ СТРУКТУРА, ОРГАНИЗАЦИЯ, КОНЦЕПТ}

Форма проведения интегрированных уроков по искусству может быть нестандартной, креативной и отражать творческий потенциал педагога (-ов), выступающих в роли модераторов и фасилитаторов деятельности учащихся. Как следствие, такие уроки бывают интересны по содержанию и форме, остаются надолго в памяти учащихся. Поэтому можно отметить эффективность такого рода занятий. За счет переключения внимания на разные аспекты изучения темы ощутимо повышаются познавательный интерес и мотивация к обучению у учащихся, как следствие, развиваются воображение, внимание, память, логическое мышление, соответственно, речь и коммуникативные навыки.

При проектировании интегрированного урока необходимо последовательно:

а) определить цель и задачи урока в связи с конкретной ситуацией и необходимость развития определенных компетенций;

б) ограничить сферу интеграции и аргументированно обосновать критерии для объединения учебного материала, а именно определить единую предметную область (тему), находящуюся на стыке разных дисциплин, но позволяющую составить целостное представление об объекте изучения;

в) выделить наиболее важные, «узловые» моменты, в связи с чем продумать связанные с ними развивающие задания;

г) не забывать о таком важном принципе проектирования урока, как определение соотношения знакомого и нового материала. Последний обязательно должен основываться на опыте и уже имеющихся у учащихся соответствующих знаниях.

Организационная сторона проведения интегрированного урока должна строить на взаимодействии педагогов-фасилитаторов, которое может быть представлено в двух вариантах:

1) паритетное, т. е. с равным долевым участием каждого из учителей;

2) соподчинение, когда один выступает в роли ведущего фасилитатора, а другой (другие) - в роли его ассистента и (или) консультанта, наблюдателя или гостя.

Представленный универсальный алгоритм работы при планировании интегрированного урока необходимо конкретизировать. Приведем в пример возможный вариант интегрированного занятия по теме «М. П. Мусоргский. Сюита "Картинки с выставки”. Аесятая (финальная часть) сюиты “Богатырские ворота. В стольном городе во Киеве” », в основу которого положен опыт проведения автором учебного мероприятия для курсантов Уральского юридического института Министерства внутренних дел Российской Федерации в мае 2016 г. 
Казалось бы, одна небольшая тема, но при внимательном рассмотрении истории создания музыкального творения Мусоргского вдруг открывается возможность провести урок, затрагивающий актуальные темы сегодняшнего дня.

Известно, что сюита «Картинки с выставки», состоящая из десяти пьес с интермедиями, была создана композитором в 1874 г. в память о друге, художнике и архитекторе В. А. Гартмане, который вошел в историю искусства XIX в. как один из основоположников «русского стиля» в архитектуре.

Есть свидетельства того, что знакомство Мусоргского с Гартманом состоялось в конце 1870 г. в доме известного музыкального и художественного критика, историка искусств, архивиста, общественного деятеля В. В. Стасова. Вскоре после знакомства между архитектором и композитором установилась теплая и крепкая дружба, о которой представлено достаточно много свидетельств и в музыковедческой, и в искусствоведческой дитературе (см.: Мария Вениаминовна Юдина ... , 1978: 290-298; М. П. Мусоргский ... , 1987: 82-86; Орлова, 1994: 169, 173-175; Фрид, 1980: 212-221). Скоропостижная смерть Гартмана летом 1873 г. в возрасте 39 лет потрясла Мусоргского до глубины души.

В феврале - марте 1874 г. по инициативе Стасова и при содействии Петербургского общества архитекторов в Императорской академии художеств была проведена посмертная экспозиция работ Гартмана, в которой были представлены 415 авторских произведений: рисунки, акварели, сепии. Находясь под впечатлением работ художника, Мусоргский написал знаменитые «Картинки с выставки». Об этом, в частности, писал Стасов в 1881 г.: «Мусоргский, страстно любивший Гартмана и глубоко пораженный его смертью, задумал “нарисовать в музыке" дучшие картинки покойного своего друга, представив тут и самого себя, прогуливающимся по выставке, радостно или грустно вспоминающим о покойном высокоталантливом художнике» (Стасов, 1989: 55$)$.

Особое внимание композитора среди представленных работ Гартмана привлек один проект, с которым связана следующая история.

4 (16) апреля 1866 г. была совершена первая попытка убийства российского императора Александра II (как известно, всего террористами-народовольцами было совершено несколько покушений на жизнь императора). Стрелявшего в императора террориста-революционера Амитрия Каракозова своевременно толкнул находившийся рядом человек, и пуля пролетела выше головы Александра II. Так, при удачном стечении обстоятельств было предотвращено убийство российского императора (Кошель, 1995).

Спустя некоторое время в честь спасения Александра II было принято решение построить грандиозные ворота в Киеве. Аля этого был организован конкурс, на котором эскиз ворот Гартмана, выполненных в древнерусском стиле, победил. Однако впоследствии конкурс был отменен и удачный проект не был реализован (см.: Сборник материалов для истории ..., 1866: 28; Отчет Императорской Академии ... , 1874: 369).

Впечатленный художественным замыслом Гартмана, Мусоргский написал десятую (финальную) часть сюиты «Богатырские ворота. В стольном городе во Киеве». Богатыми музыкальными выразительными средствами композитор передает стойкий дух богатырей земли русской, могучую силу народа, величие столицы древнего государства восточных славян. Торжественные аккорды, перезвон колоколов празднично и радостно завершают гениальное произведение русского композитора, рисуя «образ величавой звонкоголосой сильной Руси» (Мутья, 1999: 38). 
Определим, материалы каких учебных дисциплин могут быть использованы при проведении интегрированного урока по представленной теме.

Во-первых, это конечно же история и обществознание. Затем, и это во-вторых, педагогу необходимо включить материал по разным видам искусства, что позволит сформировать необходимые 3УН (знания, умения, навыки) у учащихся.

Начнем с исторического материала. Известно, что император Александр II вступил на престол 19 февраля 1855 г. после смерти отца Николая I.

Политическое и военное положение России в этот период было близко к катастрофическому. Шла Крымская война, которая для России велась крайне неудачно. И вынужденно заключив Парижский мирный договор 6 марта 1856 г. на невыгодных для России условиях, Александр II смог минимизировать возможные потери.

В целом за время своего правления император Александр II провел несколько важных реформ. Это так называемые Великие реформы 60-70-х годов XIX в.: военная 1861 г., после которой рекрутская повинность сменилась срочной службой; народного образования 1863-1864 гг., в результате которой расширились права университетов; земская, судебная, городская 1864 г. Понимая, что феодально-крепостническая система хозяйствования исчерпала себя, Александр II принимает важное решение по отмене крепостного права в России - 3 марта 1861 г. издает манифест об освобождении крестьян от крепостной зависимости.

Также необходимо отметить, что за время правления Александра II к России были присоединены новые территории - Кавказ, Туркестан, Приамурье, Уссурийский край, Курильские острова (в обмен на южную часть Сахалина), возвращен Севастополь в обмен на турецкую крепость Каре. Были налажены дипломатические отношения со многими европейскими странами.

Несмотря на проводимые императором либеральные реформы, в России нарастало революционное движение. На жизнь императора неоднократно покушались (1866, 1867, 1879 и 1880 гг.). И 13 марта 1881 г., в день, когда Александр II решился дать ход проекту первой российской конституции, российский император был убит народовольцами в Петербурге. Великие реформы остались незавершенными.

Так представленная тема интегрированного урока обращает к проблеме терроризма. Аень первого покушения на Александра II - 4 апреля 1866 г., когда у ворот петербургского Аетнего сада суетливый молодой человек пытался застрелить из пистолета императора, - считают началом терроризма в России (Кошель, 1995). Ао этого Россия знала дворцовые перевороты, были убиты императоры Иоанн VI, Петр III и Павел I, но впервые целью покушения становился не захват власти, не попытка изменить династический порядок, а некая абстрактная и плохо сформулированная политическая идея.

Террористами не рождаются, террористами становятся. Психические особенности личности, наложенные на внешние обстоятельства, могут подвести человека к террористическому акту. Сам Амитрий Каракозов, а именно он был тем молодым человеком, стрелявшим 4 апреля 1866 г. в Александра II, объяснял свой поступок психическим расстройством. О себе он говорил, что он человек болезненный, нервный и вместе с тем нерелигиозный. У поддавшегося влиянию прокламаций - листовок, призывающих к активным политическим действиям, Каракозова родилась идея совершить террористический акт (см. : Покушение ..., 1926).

По решению суда 3 сентября 1866 г. Амитрий Каракозов был казнен (Георгиева, Георгиев, Орлов, 2012: 215). 
В последние годы терроризм захлестнул многие страны. Не случайно его называют и «чумой XXI века», и «глобальной угрозой современности» (Горбунков, 2012; Кожушко, 2000; Никитин, 2009; Терроризм - угроза ... , 2003; Требин, 2004; Федоров, 2005). Террористические действия могут быть разнообразны, но все их объединяют два общих элемента. Во-первых, они направлены на подрыв государственной власти и, во-вторых, создают у населения чувства страха и беспомощности, возникающие под влиянием организованного и жестокого насилия террористов.

Сегодня в государстве разрабатываются меры по противодействию терроризму. Главными принципами борьбы с терроризмом признаются: законность, реализация мер по предупреждению терроризма, неотвратимость наказания виновных. Уголовный кодекс Российской Федерации (ст. 205) классифицирует терроризм следующим образом: это «совершение взрыва, поджога или иных действий, создающих опасность гибели людей, причинения значительного имущественного ущерба либо наступления иных общественно опасных последствий, если эти действия совершены в целях нарушения общественной безопасности, устрашения населения либо оказания воздействия на принятие решений органами власти, а также угроза совершения указанных действий в тех же целях...» (Уголовный кодекс ... : Электронный ресурс).

Современное молодое поколение должно осознать, что терроризм сопряжен с агрессией, отрицанием общечеловеческих ценностей, и помнить о жестокости и бессмысленности таких преступлений.

Необходимо отметить роль исторической памяти в общественном сознании, под которой понимают коллективный опыт сохранения и осмысления исторических событий прошлого (Ассман, 2014; Васильев, 2012; Герасимов, 2013; Ростовцев, Сосницкий, 2014; Хальбвакс, 2007). При этом нужно учитывать, что историческая память не представляет собой систему абстрактных фактологических знаний, она есть важный и необходимый инструмент поддержания национальной идентичности, который включает «набор» передаваемых из поколения в поколение исторических сообщений, преломленных глубоким анализом через призму настоящего.

Нельзя не отметить тот факт, что историческая память всегда связана, с одной стороны, с оценкой, с другой - с забвением. Аюдям, как и отдельному человеку, свойственно забывать что-то из прошлого. И порой, либо бессознательно, либо целенаправленно вычеркивая из памяти значимое, искаженно оценивать отдельные исторические события.

Особую роль в поддержании коллективной памяти играет искусство, которое благодаря символической реконструкции способно оживлять в памяти людей исторически значимое посредством художественных образов.

\section{ПАМЯТНИК ИСТОРИИ И ИСТОРИЧЕСКАЯ ПАМЯТЬ}

В контексте представленной темы интегрированного урока можно обратиться к такому памятнику истории и культуры Аревнерусского государства, как Золотые ворота в Киеве.

Известно, что Золотые ворота были установлены во время правления князя Ярослава Мудрого. Это древнее фортификационное сооружение, возведенное в честь победы над печенегами, с одной стороны, представляет собой уникальный памятник оборонного строительства, с другой - выдающееся творение мастеров древнего зодчества. В XI в. вместе с Софийскими, Аядскими и $\Lambda$ ьвовскими воротами, валом и рвом они составляли единую оборонительную систему Киева. 
Есть две версии названия ворот. По одной версии, название «золотые» они получили от позолоченных куполов надвратной церкви, освященной в честь Благовещения Божией Матери (Шулькевич, Амитренко, 1982). По другой версии, название было заимствованным - «золотыми» называли ворота в столице Византийской империи Константинополе. Здесь необходимо акцентировать внимание учащихся на таком судьбоносном историческом событии, как принятие византийского (православного) варианта христианства Аревнерусским государством - Киевской Русью.

Помимо оборонных целей, Золотые ворота также предназначались для церемониальных (триумфальных) въездов и выездов - здесь тождественно встречали и провождали княжеские дружины, именитых гостей и послов. Во многом это связано с тем, что ворота были основным сухопутным входом в Киев с юго-западной стороны.

Сооружение поражало не только своим величием и неприступностью, но и таким отличным от западноевропейских традиций новшеством, как наличие мощной боевой башни в виде белокаменной церкви, что было очень символично для православного города.

Судьба памятника, как и многих древних строений, трагична: в 1240 г. во время осады и взятия города полчищами Батыя ворота оказались сильно разрушенными и практически превратились в руины; в середине XVIII в. из-за угрозы нападения турок остатки ворот были засыпаны, а рядом были установлены новые по проекту инженера A. Аебоскета. Только в XIX в. были предприняты попытки расчистить и реконструировать знаменитое сооружение. Полностью выполнить реконструкцию оказалось возможным только к празднованию 1500-летия Киева, которое отмечалось в 1982 г.

Вообще, в контексте происходящих в мире политических событий необходимо акцентировать внимание учащихся на том факте, что Киев является историческим центром восточнославянской суперэтнической общности, представленной тремя братскими народами - русским, украинским и белорусским. И какие бы политические события ни провоцировали разрыв отношений между Россией, Украиной и Белоруссией, народы представленных стран должны помнить свой исторический и культурный опыт; сохраняя свою идентичность, поддерживать братские отношения. Сегодня в условиях цивилизационных разломов, по концепции С. Хантингтона (Хантингтон, 2003), так важно осознать необходимость сохранения православно-христианской цивилизации, найти правильные политические решения по консолидации славянского мира и поддержанию его идентичности.

\section{ЗАКАЮЧЕНИЕ}

Подготовить и провести интегрированный урок не просто, но при всех объективных трудностях, с которыми сталкиваются педагоги, необходимо отметить важность включения их в образовательную практику. Интеграция образовательных областей дает возможность показать новому поколению мир во всем его многообразии с привлечением естественно-научных и социогуманитарных знаний, а также музыки, живописи, театра, что способствует как интеллектуальному, так и эмоциональному развитию личности каждого учащегося, формированию его творческого и логического мышления. Также интегрированные уроки вносят новизну в обучение, повышают мотивацию, формируют познавательный интерес, способствуют формированию целостной картины мира, позволяют систематизировать знания, способствуют развитию внимания, воображения, памяти, мышления учащихся, повышению уровня их обучен- 
ности и воспитанности. Таким образом, интегрированные практики обучения и воспитания позволяют создать все необходимые предпосылки для всестороннего развития детей, подростков и юношества.

\section{СПИСОК АИТЕРАТУРЫ}

Ассман, А. (2014) Алинная тень прошлого. Мемориальная культура и историческая политика : пер. с нем. М. : Новое литературное обозрение. 322 с.

Васильев, А. (2012) Memory studies: единство парадигмы - многообразие объектов (обзор англоязычных книг по истории памяти) // Новое литературное обозрение. Вып. 5 (117). C. $461-480$.

Виневская, А. В. (2014) Педагогические технологии. Вопросы теории и практики внедрения : справочник для студентов. Ростов н/А. : Феникс. 253 с.

Георгиева, Н. Г., Георгиев, В. А., Орлов, А. С. (2012) Исторический словарь. 2-е изд. М. : Проспект. 591 с.

Герасимов, О. В. (2013) Феномен исторической памяти // Вестник Университета Российской академии образования. №5 (68). С. 133-137.

Гриценко, А. И. (2008) Теория и практика обучения: интегративный подход : учеб. пособие для студентов высших учебных заведений, обучающихся по специальностям «Педагогика и психология», «Педагогика». М. : Академия. 237 с.

Горбунов, К. Г. (2012) Терроризм: история и современность : социально-психологическое исследование. М. : Форум. 398 с.

Игнатов, С. Б., Игнатова, В. А. (2013) Интегративный подход в моделировании современного образования // Социально-экологические технологии. № 1. Т. 1. С. 99-105.

Кожушко, Е. (2000) Современный терроризм. Анализ основных направлений. Минск : Харвест. 448 с.

Кошель, П. А. (1995) История наказаний в России; История российского терроризма. М. : Голос. 369, [2] с.

Мария Вениаминовна Юдина. Статьи. Воспоминания. Материалы (1978) / сост. и ред. А. Кузнецов. М. : Советский композитор. 416 с. $191 \mathrm{c}$

М. П. Мусоргский [Альбом] / сост., автор вступ. ст. и текста Р. Ширинян. М. : Музыка, 1987.

Мутья, Н. Н. (1999) Творчество Виктора Александровича Гартмана, 1834-1873 : автореф. дис. ... канд. искусствоведения. СПб. 40 с.

Никитин, А. И. (2009) Конфликты, терроризм, миротворчество. М. : Navona. 231 с.

Орлова, А. А. (1994) Мусоргский в Петербурге. $\Lambda$. : Аениздат. 220 с.

Отчет Императорской Академии Художеств с 4 ноября 1872 г. по 4 ноября 1873 г. (1874). СПб. : Типография Императорской Академии Художеств. 142 с.

Покушение Каракозова 4 апреля 1866 г. (1926) // Красный архив (исторический журнал). T. 4 (17). C. 118-124.

Ростовцев, Е. А., Сосницкий, А. А. (2014) Направления исследований исторической памяти в России // Вестн. С.-Петерб. ун-та. Сер. 2. История. № 2. С. 106-126.

Сборник материалов для истории Императорской С.-Петербургской Академии Художеств за сто лет ее существования (1866) : в 3 т. / под ред. П. Н. Петрова. СПб. : Типография Комиссионера Императорской Академии Художеств Гогенфельдена и Ко. Т. 3.424 с.

Стасов, В. В. (1989) Модест Петрович Мусоргский // М. П. Мусоргский в воспоминаниях современников / сост. Е. М. Гордеева. М. : Музыка. 318 с.

Терроризм - угроза человечеству в XXI веке (2003) : ст. / отв. ред. Р. Б. Рыбаков. М. : ИВ РАН : Крафт+. 267 с.

Требин, М. П. (2004) Терроризм в ХХІ веке. Минск : Харвест. 810 с.

Уголовный кодекс Российской Федерации от 13.06.1996 № 63-Ф3 (ред. от 06.07.2016) [Электронный ресурс] // КонсультантПлюс. URL: http://www.consultant.ru/document/cons_doc_ LAW_10699/ (Аата обращения: 12.05.2016). 
Федоров, Ю. Е. (2005) Современный терроризм: особенности и перспективы. М. : МГИМО Университет. 80 с.

Фрид, Э. А. (1980) Картинки с выставки // Русская музыкальная литература : учеб. пособие для муз. училищ / сост. и общ. ред. Э. $\Lambda$. Фрид. 6-е изд., испр. и доп. Вып. 2. $\Lambda$. : Музыка : $\Lambda$ нингр. отА-ние. 295 с. С. 212-221.

Хальбвакс, М. (2007) Социальные рамки памяти : пер. с фр. М. : Новое издательство. 346 с.

Хантингтон, С. (2003) Столкновение цивилизаций : пер. с англ. М. ; СПб. : АСТ. 603 с.

Харунжев, А. А., Харунжева, Е. В. (2003) Интегрированный урок как один из способов формирования информационной культуры // Интеграция образования. № 3. С. 84-89.

Шулькевич, М. М., Амитренко, Т. А. (1982) Киев: Архитектурно-исторический очерк. 6-е изд. Киев : Будівельник. 448 с.

Аата поступления: 05.07.2016 2.

\section{CULTURAL PRACTICES IN EDUCATION: \\ THE CONSTRUCTIVE POTENTIAL OF INTEGRATED LESSON \\ M. S. INKIZHEKOVA \\ (EDUCATION DEVELOPMENT INSTITUTE IN SVERDLOVSK REGION, URAL JURIDICAL INSTITUTE OF THE MINISTRY OF INTERNAL AFFAIRS OF THE RUSSIAN FEDERATION)}

In connection with the introduction Federal state educational standards becomes relevant to the development of an integrative approach as one of the phenomena of cultural practices in education, familiarization with its basic principles and essence. The need for new educational technologies, innovation methods and techniques used in the framework of integrative education, caused by the objective necessity of perfection of professional-pedagogical competences of teachers.

In modern conditions when integration processes in the development of education and science of acquiring new forms that appeal to the approach based on the cognition of phenomena, processes and States in their systemic unity, allows to form in students a holistic and however tiered view of the world. The article presents an example: the algorithm works on the planning and organization of an integrative lesson on «Modest Mussorgsky. Tenth (final) part of the "Giant gate. In the capital city of Kiev», the Suite «Pictures at an exhibition». The author shows that the topic with the involvement of educational material on history, science, and disciplines of the subject area «Art» can reveal not only interconnected world of artistic images, but also to address the current problems of the contemporary socio-cultural reality.

The author concludes that the lesson is built on the interdisciplinary integration of multilevel and ethnopragmatics knowledge in educational space of the modernizing of school comes the constructive variant of systematization of educational material. In the context of integrated lesson reveals a new functional role of the teacher, who acts not so much in the role of translator of knowledge but facilitator's assistant and mentor.

Keywords: integrated lesson; interdisciplinary integration; teacher is facilitator; cultural practices; M. P. Mussorgsky; history of Russia; terrorism; the «Golden gate»

\section{REFERENCES}

Assman, A. (2014) Dlinnaia ten' proshlogo. Memorial'naia kul'tura i istoricheskaia politika, transl. by Germ. Moscow, Novoe literaturnoe obozrenie. 322 p. (In Russ.)

Vasil'ev, A. (2012) Memory studies: edinstvo paradigmy - mnogoobrazie ob»ektov (obzor angloiazychnykh knig po istorii pamiati). Novoe literaturnoe obozrenie, vol. 5 (117), pp. 461-480. (In Russ.)

Vinevskaia, A. V. (2014) Pedagogicheskie tekbnologii. Voprosy teorii i praktiki vnedreniia: spravochnik dlia studentov. Rostov na Donu, Feniks. 253 p. (In Russ.)

Georgieva, N. G., Georgiev, V. A. and Orlov, A. S. (2012) Istoricheskii slovar'. 2-s ed. Moscow, Prospekt. 591 p. (In Russ.) 
Gerasimov, O. V. (2013) Fenomen istoricheskoi pamiati. Vestnik Universiteta Rossiiskoi akademii obrazovaniia, no. 5 (68), pp. 133-137. (In Russ.)

Gritsenko, L. I. (2008) Teoriia i praktika obucheniia: integrativnyi podkbod: ucheb. posobie dlia studentov vysshikh uchebnykh zavedenii, obuchaiushchikhsia po spetsial'nostiam «Pedagogika i psikhologiia», «Pedagogika». Moscow, Akademiia. 237, [2] p. (In Russ.)

Gorbunov, K. G. (2012) Terrorizm: istoriia i sovremennost' : sotsial'no-psikhologicheskoe issledovanie. Moscow, Forum. 398 p. (In Russ.)

Ignatov, S. B. and Ignatova, V. A. (2013) Integrativnyi podkhod v modelirovanii sovremennogo obrazovaniia. Sotsial'no-ekologicheskie tekbnologii, no. 1, vol. 1, pp. 99-105. (In Russ.)

Kozhushko, E. (2000) Sovremennyi terrorizm. Analiz osnovnykh napravlenii. Minsk, Kharvest. 448 p. (In Russ.)

Koshel', P. A. (1995) Istoriia nakazanii v Rossii; Istoriia rossiiskogo terrorizma. Moscow, Golos. 369 p. (In Russ.)

Mariia Veniaminovna Iudina. Stat'i. Vospominaniia. Materialy (1978) / comp., ed. A. Kuznetsov. Moscow, Sovetskii kompozitor. 416 p. (In Russ.)

M. P. Musorgskii [Al'bom] (1987) / comp. R. Shirinian. Moscow, Muzyka. 191 p. (In Russ.)

Mut'ia, N. N. (1999) Tvorchestvo Viktora Aleksandrovicha Gartmana, 1834-1873 : Thesis of Diss. ... Candidate of Art Sciences. St. Petersburg. 40 p. (In Russ.)

Nikitin, A. I. (2009) Konflikty, terrorizm, mirotvorchestvo. Moscow, Navona. 231 p. (In Russ.)

Orlova, A. A. (1994) Musorgskii v Peterburge. Leningrad, Lenizdat. 220 p. (In Russ.)

Otchet Imperatorskoi Akademii Kbudozhestv s 4 noiabria 1872 g. po 4 noiabria 1873 g. (1874).

St. Petersburg, Tipografiia Imperatorskoi Akademii Khudozhestv. 142 p. (In Russ.)

Pokushenie Karakozova 4 aprelia 1866 g. (1926). Krasnyi arkhiv (istoricheskii zhurnal), vol. 4 (17), pp. 118-124. (In Russ.)

Rostovtsev, E. A. and Sosnitskii, D. A. (2014) Napravleniia issledovanii istoricheskoi pamiati v Rossii. Vestn. S.-Peterb. un-ta, issue 2. Istoriia, no. 2, pp. 106-126. (In Russ.)

Sbornik materialov dlia istorii Imperatorskoi S.-Peterburgskoi Akademii Kbudozhestv za sto let ee sushchestvovaniia (1866) : in 3 vol. / ed. P. N. Petrova. St. Petersburg, Tipografiia Komissionera Imperatorskoi Akademii Khudozhestv Gogenfel'dena i Ko. Vol. 3. 424 p. (In Russ.)

Stasov, V. V. (1989) Modest Petrovich Musorgskii. In: M. P. Musorgskii v vospominaniiakh sovremennikov, comp. E. M. Gordeeva. Moscow, Muzyka. 318 p. (In Russ.)

Terrorizm - ugroza chelovechestvu $v$ XXI veke (2003), ed. R. B. Rybakov. Moscow, IV RAN, $\mathrm{Kraft}+.267$ p. (In Russ.)

Trebin, M. P. (2004) Terrorizm v XXI veke. Minsk : Kharvest. 810 p. (In Russ.)

Ugolovnyi kodeks Rossiiskoi Federatsii ot 13.06.1996 № 63-FZ (red. ot 06.07.2016). Konsul'tantPlius [online] Available at: http://www.consultant.ru/document/cons_doc_LAW_ 10699/ (access data: 12.05.2016). (In Russ.)

Fedorov, Iu. E. (2005) Sovremennyi terrorizm: osobennosti i perspektivy. Moscow, MGIMO Universitet. 80 p. (In Russ.)

Frid, E. L. (1980) Kartinki s vystavki. In: Russkaia muzykal' naia literatura : ucheb. posobie dlia muz. Uchilishch, comp., ed. E. L. Frid. 6s ed. Vol. 2. Leningrad, Muzyka, Leningr. otd-nie. 295 p. Pp. 212-221. (In Russ.)

Khal'bvaks, M. (2007) Sotsial'nye ramki pamiati, transl. by Fr. Moscow, Novoe izdatel'stvo. 346 p. (In Russ.)

Khantington, S. (2003) Stolknovenie tsivilizatsii, transl. by English. Moscow, St. Petersburg, AST. 603 p. (In Russ.)

Kharunzhev, A. A. and Kharunzheva, E. V. (2003) Integrirovannyi urok kak odin iz sposobov formirovaniia informatsionnoi kul'tury. Integratsiia obrazovaniia, no. 3, pp. 84-89. (In Russ.)

Shul'kevich, M. M. and Dmitrenko, T. D. (1982) Kiev: Arkbitekturno-istoricheskii ocherk. $6 \mathrm{~s}$ ed. Kiev, Budivel'nik. 448 p. (In Russ.)

Submission date: 05.07.2016. 
Инкижекова Мария Сергеевна - доктор философских наук, доцент, профессор кафедры художественного образования Института развития образования Свердловской области; профессор кафедры общей психологии, гуманитарных и социальных дисциплин Уральского юридического института Министерства внутренних дел Российской Федерации. Адрес: 620137, Россия, г. Екатеринбург, ул. Академическая, д. 16. Тел./факс: +7 (343) 369-29-86. Эл. адрес: masha ink@mail.ru

Inkizhekova Mariia Sergeevna, Doctor of Philosophy, Associate Professor, Professor of Department of art education of the Institute of education development in Sverdlovsk region; Professor of Department of General psychology, Humanities and Social science of the Ural juridical Institute of the Ministry of internal Affairs of the Russian Federation. Postal address: 620137, 16 Academic St., Yekaterinburg, Russian Federation, 620137. Tel./fax:+7 (343) 369-29-86. E-mail: masha_ink@mail.ru 